Research Article

\title{
Dynamic Tensile Properties of Granite Varied with Depths under a Similar Loading Rate
}

\author{
Ke Man (iD, 1,2 Ju Wang, ${ }^{1,2}$ and Xiaoli Liu $\mathbb{D}^{3}$ \\ ${ }^{1}$ Division of Environment Engineering, Beijing Research Institute of Uranium Geology, Beijing 100029, China \\ ${ }^{2}$ Key Laboratory of China National Nuclear Corporation on High Level Radioactive Waste Geological Disposal, \\ Beijing 100029, China \\ ${ }^{3}$ State Key Laboratory of Hydroscience and Hydraulic Engineering, Tsinghua University, Beijing 100084, China
}

Correspondence should be addressed to Ke Man; man_ke@sina.cn

Received 11 August 2018; Revised 17 October 2018; Accepted 7 November 2018; Published 22 November 2018

Guest Editor: Li Chen

Copyright (c) $2018 \mathrm{Ke}$ Man et al. This is an open access article distributed under the Creative Commons Attribution License, which permits unrestricted use, distribution, and reproduction in any medium, provided the original work is properly cited.

\begin{abstract}
Based on the SHPB device, the dynamic tensile test was carried out on the granite, which is located at the depth $350 \mathrm{~m} \sim 580 \mathrm{~m}$ at the same borehole in TianHu area Xinjiang Province, the preselected site of the high-level radioactive waste geological disposal in China. Under the loading rate level of $10^{5} \mathrm{MPa} / \mathrm{s}$, the dynamic tensile strength is generally between $15 \mathrm{MPa} 35 \mathrm{MPa}$, which is of significant reference for the site selection. No matter whatever the depth, the dynamic tension strength increases with the loading rate, which shows the loading rate effect of brittle material. Meanwhile, the failure model is also tension pattern, which is the same as the static tension test. Furthermore, as the physical characteristics of the rock have been changed gradually, the rock strength and other mechanical properties will increase or decrease with the depth. From the point of physical mechanism, the density, porosity, and others are different at diverse depths, which lead to the differences of mechanical properties. And the result and the theoretical knowledge could be applied to the blasting and excavation of deep geoengineering and HLW geodisposal.
\end{abstract}

\section{Introduction}

With the development of geotechnical engineering in the deep construction, including the hydraulic and hydropower engineering, underground tunnel construction, even nuclear waste geological disposal, and so on, as the buried depth increases, the disasters are also increasing. Rock mechanics related to deep geotechnical engineering is a hotspot for scholars at home and abroad, and a large number of results have been achieved [1-6]. In the field of geological disposal of high radioactive waste, the mechanical properties of rock mass are directly related to the stability of underground engineering related to the design, construction, and operation. The characteristics of strength, deformation, crack propagation mechanism, and permeability of rock mass should be researched in detail. As rock is influenced by the high thermo, high in-site stress, high seepage pressure, and excavation disturbance under the deep geological conditions, the deformation and failure characteristics are obviously different from those of shallow depth, and the mechanical behavior is more complex and complicated $[7,8]$.

Through the uniaxial and triaxial mechanical tests of different depth in basalt in Beijing DaTai coal mine by Zhou et al. [9], it is shown that the density of basalt, uniaxial compression strength, tensile strength, elastic modulus, cohesive force, and internal friction angle increased linearly with the depth, but Poisson's ratio was opposite. Jiang et al. [10] also found that the elastic modulus, compressive strength, and tensile strength increased with the depth through the laboratory test on granite.

Rock static parameters, such as compressive strength, tensile strength, deformation, elastic modulus, Poisson's ratio, friction coefficient, cohesive force, and so on, plays a guiding role in the design, construction, support, and monitoring of rock engineering. However, the dynamic behavior of rock is also important for the engineering [11-13]. 
Before the project excavation, the rock has been in a certain crustal stress state, that is, the rock has been under a static stress state before bearing the dynamic load. Not only affected by high crustal stress, but also rock is superimposed by dynamic loads such as mining disturbance and even earthquakes [14-16]. Rock dynamic parameters also include the mechanical and physical quantities corresponding to the static parameters, such as dynamic compressive strength, dynamic tensile strength, dynamic elastic modulus, and dynamic Poisson's ratio and so on. To study the rock engineering, it is not enough to just consider the static load or the dynamic load [17-20]. The most important researches related to rock dynamics are blasting engineering, protective engineering, and seismic engineering, and the antiseismic and vibration reduction of engineering are the most important issues. Sometimes, it can meet the requirements of engineering reality, but in some cases, it is still insufficient $[11,21,22]$.

Furthermore, when the dynamic properties of rock have been obtained, the engineering design method could be modified and improved, such as the empirical criterion on the rock failure, in which the index of uniaxial compression strength could be replaced by the dynamic compression strength, which is much more suitable for the blasting situation. And during the rock support engineering, the rock bolt could be calculated using the dynamic strength, especially for the blot bearing dynamic tension condition [23-25].

Under the condition of high in-site stress, rock burst in deep mine is still a difficulty to be solved urgently, which is considered to be monitored by the blasting vibration, advanced detection, and so on [26]. The vibration characteristics of various experimental equipment in the chamber of high-level radioactive waste geological disposal at different depth, as well as their durability and safety, are also urgently needed to be solved. At present, the basic dynamic characteristics, such as dynamic tensile strength, dynamic compression strength, dynamic elastic modulus, and dynamic fracture toughness of rock with different depth have not been studied systematically [27]. Therefore, it is of great significance to study the dynamic behavior of rock under deep depth.

Tianhu area, Xinjiang Province, as one of the preferred areas for the geological disposal of high-level radioactive waste in China, is gradually carrying out the mechanical tests of granite in this area. The static and dynamic mechanical properties were studied by Man et al. [28], and it is found that the dynamic mechanical strength and the coupled static and dynamic tensile strength shown the loading effect.

However, the specimens are selected at the same depth ( $360 \mathrm{~m}$ or so), and the rock dynamic characteristics of different depths are not studied. Particularly, the tensile property of rock is an important characteristic, as the rock failure is often caused by tensile stress. Therefore, in view of the drilling borehole in Tianhu area, this paper further implemented the dynamic tensile tests of different depth. Through the analysis and discussion of the experimental data, it can be supported to the design, construction and monitoring of the geotechnical engineering.

\section{Testing Schemes}

2.1. Impact Testing Equipment. The dynamic parameter has been achieved using SHPB system with a $75 \mathrm{~mm}$ diameter (Figure 1), which is designed by Central South University.

In order to eliminate the $\mathrm{P}-\mathrm{C}$ oscillation, a stable semisinusoidal wave is required, which means that the rising segment of the loading wave should be settled in about $100 \mu \mathrm{s}$. And the spindle type impact bullet is used in the emitter. The material and the maximum diameter of the bullet are the same as that corresponding to the incident and transmission bars, and the constant strain rate can be realized by the produced semisinusoidal stress wave. Meanwhile, the parameters of the SHPB are illustrated in Table 1.

2.2. Specimen Preparation. Granite with better integrity and homogeneity is selected. The core is drilled in a depth ranges from $350 \mathrm{~m}$ to $580 \mathrm{~m}$, and the specimen numbers are uniformly numbered in order of $H$ (depth)- $X$ (No.). Totally, the buried depth is $350 \mathrm{~m}, 360 \mathrm{~m}, 380 \mathrm{~m}, 420 \mathrm{~m}, 510 \mathrm{~m}, 520 \mathrm{~m}$, $530 \mathrm{~m}, 540 \mathrm{~m}$, and $580 \mathrm{~m}$ separately. According to the conventional specimen requirement for rock mechanics, the samples are manufactured.

The rock core drilling machine, the cutting machine and the grinding machine should be used for fine processing to prepare the specimen to meet the testing standard. According to the standard of the rock testing method GB/T 50266-2013 [29]. All the test specimens are uniformly processed into a cylinder with a standard size. The specimen is Brazilian disc, which the size is about $\Phi 50 \mathrm{~mm} \times H 25 \mathrm{~mm}$, corresponding to the Diameter $\times$ Height. The deviation of the roughness of the specimen at both ends is $0.05 \mathrm{~mm}$, the allowable deviation of height and diameter is $0.3 \mathrm{~mm}$, and the section should be perpendicular to the axis while the allowable deviation is 0.25 degrees [30].

The geometric size, density, and longitudinal wave velocity of the processed specimens were measured. A part of the rock specimen is shown in Figure 2.

\section{Dynamic Tensile Testing}

Damage caused by excavation becomes more and more obvious, so the study on dynamic mechanical properties of rock is important. It should be noticed that the mechanical response of rock under the dynamic load is completely different from that under the static load, which is caused by the inertia effect and the dynamic rate effect of the rock. Under the dynamic impact or blasting, the internal particles of the rock can be destroyed by the external force. Because of the inertia effect, the particles are damaged by different mechanical properties. That is to say, different loading rates cause different failure forms. The phenomenon has a strong guiding significance for practical projects. Thus, the dynamic tensile tests have been applied to the specimen under different depths.

The control parameters and test procedures in the dynamic tensile test are as follows: The specimens are under 

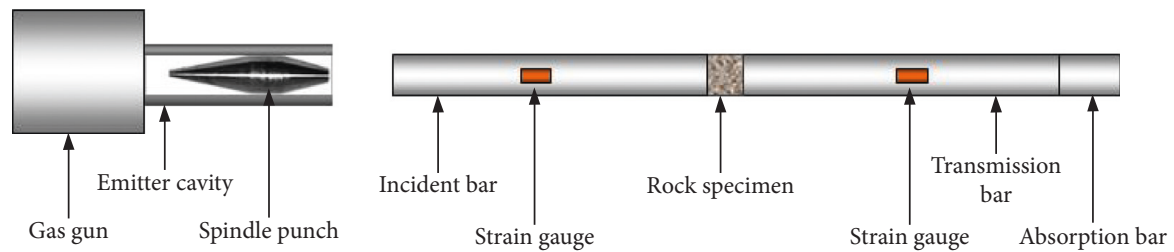

Figure 1: Schematics of SHPB setup.

TABLe 1: Parameters of SHPB.

\begin{tabular}{lccccccc}
\hline $\begin{array}{l}\text { Diameter of } \\
\text { the bar }(\mathrm{mm})\end{array}$ & $\begin{array}{c}\text { Length of the } \\
\text { input bar }(\mathrm{mm})\end{array}$ & $\begin{array}{c}\text { Length of the } \\
\text { output bar }(\mathrm{mm})\end{array}$ & $\begin{array}{c}\text { Elastic modulus } \\
(\mathrm{GPa})\end{array}$ & $\begin{array}{c}\text { Longitudinal } \\
\text { wave velocity }\end{array}$ & $\begin{array}{c}\text { Poisson } \\
\text { ratio }\end{array}$ & $\begin{array}{c}\text { Pressure } \\
(\mathrm{MPa})\end{array}$ & $\begin{array}{c}\text { Density } \\
\left(\mathrm{kg} \cdot \mathrm{m}^{-3}\right)\end{array}$ \\
\hline 75 & 2000 & 2000 & 250 & 5400 & 0.285 & $0 \sim 10$ & 7810 \\
\hline
\end{tabular}

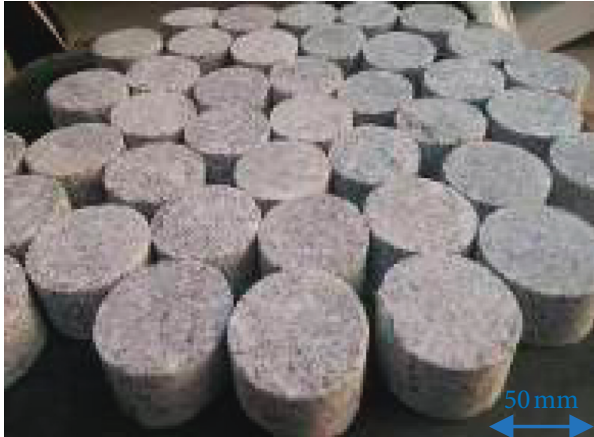

Figure 2: Rock specimen.

air-dry condition, and the test was carried out at room temperature. Firstly, in order to verify the stability of the system, the testing system without specimen has been impacted. Secondly, whether the input bar connects with the output bar closely and the impact waves coincides with the SHPB principle is monitored. Thirdly, the specimen with different loading speeds has been stricken using the SHPB. It should be noticed that the initial impact velocity is calculated using the static tensile strength data. Then, the strain and stress of the specimen could be obtained by the dynamic stress wave equations, and the testing data should be checked using the dynamic force balance method. In the end, the dynamic tensile strength of the specimen tested has been calculated by means of the dynamic stress at the failure point.

It should be noticed that the rock sample is vertically placed between the incident bar and the transmit bar when the dynamic tensile test is carried out [31]. That is to say, the two sides of rock sample are contacted with the incident bar and the transmit bar, respectively, and then the line to surface contact is achieved. This method of placing specimens here is based on the loading method adopted in the static Brazilian splitting tensile test. By using the line to surface contact loading way, the splitting failure of brittle materials can be realized, and the tensile strength of rock materials can be obtained by elastic mechanics.

The calculation method of dynamic tensile strength can be referred to the static Brazil splitting tensile test. The following formula is used here:

$$
\sigma_{\mathrm{d}}=\frac{2 P_{\max }}{\pi D L}
$$

where, $L$ and $D$ are the length and the diameter of the specimen separately and $P_{\max }$ is the maximum force value between the two side of the specimen, which can be calculated as follows:

$$
P(t)=\frac{P_{1}(t)+P_{2}(t)}{2}=E A \frac{\left[\varepsilon_{\mathrm{I}}(t)+\varepsilon_{\mathrm{R}}(t)+\varepsilon_{\mathrm{T}}(t)\right]}{2},
$$

where $A$ and $E$ refer to the sectional area and elastic modulus of the input bar or output bar, respectively; $P_{1}(t)$ and $P_{2}(t)$ refer to the force on the two sides of the specimen; $\varepsilon_{\mathrm{I}}(t)$, $\varepsilon_{\mathrm{R}}(t)$, and $\varepsilon_{\mathrm{T}}(t)$ are the strain of the incident wave, reflected wave and transmitted wave separately.

The pulse shaper technique is employed to achieve dynamic force balance in the specimen during the experiment, i.e., $P_{1}=P_{2}$. The inertial effects are thus eliminated because there is no global force difference in the specimen to induce inertial force. Consequently, the inertial effects are negligible in such cases and we can then perform quasistatic analysis.

\section{Mechanical Analysis of the Rock Strength}

The dynamic tensile impact test was carried out to obtain the dynamic tensile strength and the relationship between the strength and the strain rate. The test is also one of the basic test methods for rock dynamic characteristics.

4.1. Characteristic of the Dynamic Tensile Strength. The tensile strength is of great significance for the engineering. From the microscopic point, the failure modes of rock are mostly caused by the tensile.

Through a series of dynamic tensile tests, testing data of rock samples with different depths under diverse loading rates can be obtained, as shown in Tables 2-10.

It should be noticed that the particularity of the highlevel radioactive waste geological disposal must be considered, which means that the disposal safety cycle is long, the engineering stability demands a high level, and the excavation damaged zone should be small, so all the experimental data are listed here and are analyzed. 
TABLE 2: Testing result of the dynamic tension test at depth $350 \mathrm{~m}$.

\begin{tabular}{lcccccc}
\hline No. & $D(\mathrm{~mm})$ & $B(\mathrm{~mm})$ & $\rho\left(\mathrm{kg} / \mathrm{m}^{3}\right)$ & $V_{\mathrm{p}}(\mathrm{m} / \mathrm{s})$ & $\sigma_{\mathrm{d}}(\mathrm{MPa})$ & Loading rate $\left(10^{6} \mathrm{MPa} / \mathrm{s}\right)$ \\
\hline $350-1$ & 47.95 & 26.75 & 2661.54 & 4385.25 & 33.19 & 0.72 \\
$350-2$ & 48.05 & 26.69 & 2646.09 & 4601.72 & 26.11 & 0.32 \\
$350-3$ & 48.02 & 26.50 & 2657.97 & 4907.41 & 20.99 & 0.24 \\
$350-4$ & 48.00 & 26.70 & 2629.91 & 5037.74 & 17.25 & 0.10 \\
$350-5$ & 48.01 & 26.84 & 2635.69 & 4627.59 & 23.16 & 0.26 \\
$350-6$ & 47.98 & 26.92 & 2641.42 & 4894.55 & 27.14 & 0.30 \\
$350-7$ & 48.05 & 27.04 & 2622.04 & 4662.07 & 33.35 & 0.62 \\
\hline
\end{tabular}

TABle 3: Testing result of the dynamic tension test at depth $360 \mathrm{~m}$.

\begin{tabular}{lcccccc}
\hline No. & $D(\mathrm{~mm})$ & $B(\mathrm{~mm})$ & $\rho\left(\mathrm{kg} / \mathrm{m}^{3}\right)$ & $V_{\mathrm{p}}(\mathrm{m} / \mathrm{s})$ & $\sigma_{\mathrm{d}}(\mathrm{MPa})$ & Loading rate $\left(10^{6} \mathrm{MPa} / \mathrm{s}\right)$ \\
\hline $360-1$ & 48.21 & 26.90 & 2638.60 & 5274.51 & 27.20 & 0.37 \\
$360-2$ & 48.25 & 26.96 & 2628.36 & 5502.04 & 32.23 & 0.42 \\
$360-3$ & 48.23 & 26.79 & 2626.80 & 5581.25 & 30.94 & 0.43 \\
$360-4$ & 48.26 & 26.81 & 2631.77 & 5362.00 & 25.23 & 0.34 \\
$360-5$ & 48.22 & 26.90 & 2596.77 & 5274.51 & 34.96 & 0.51 \\
$360-6$ & 48.31 & 26.32 & 2633.75 & 5371.43 & 32.18 & 0.45 \\
$360-7$ & 48.15 & 27.76 & 2662.20 & 5237.74 & 27.80 & 0.35 \\
\hline
\end{tabular}

TABle 4: Testing result of the dynamic tension test at depth $380 \mathrm{~m}$.

\begin{tabular}{lcccccc}
\hline No. & $D(\mathrm{~mm})$ & $H(\mathrm{~mm})$ & $\rho\left(\mathrm{kg} / \mathrm{m}^{3}\right)$ & $V_{\mathrm{p}}(\mathrm{m} / \mathrm{s})$ & $\sigma_{\mathrm{d}}(\mathrm{MPa})$ & Loading rate $\left(10^{6} \mathrm{MPa} / \mathrm{s}\right)$ \\
\hline $380-5$ & 48.12 & 22.95 & 2640 & 4026 & 23.78 & 0.26 \\
$380-6$ & 48.12 & 25.48 & 2656 & 4633 & 32.28 & 0.70 \\
$380-7$ & 48.13 & 25.42 & 2636 & 3852 & 29.89 & 0.39 \\
$380-8$ & 48.25 & 24.94 & 2624 & 3614 & 35.55 & 0.88 \\
$380-9$ & 48.11 & 24.19 & 2640 & 3902 & 29.01 & 0.53 \\
$380-10$ & 48.26 & 24.62 & 2612 & 3847 & 30.77 & 0.45 \\
$380-11$ & 48.17 & 24.71 & 2628 & 3802 & 36.61 & 1.0 \\
$380-16$ & 48.30 & 24.48 & 2594 & 4080 & 34.98 & 0.85 \\
\hline
\end{tabular}

Table 5: Testing result of the dynamic tension test at depth $420 \mathrm{~m}$.

\begin{tabular}{lcccccc}
\hline No. & $D(\mathrm{~mm})$ & $H(\mathrm{~mm})$ & $\rho\left(\mathrm{kg} / \mathrm{m}^{3}\right)$ & $V_{\mathrm{p}}(\mathrm{m} / \mathrm{s})$ & $\sigma_{\mathrm{d}}(\mathrm{MPa})$ & Loading rate $\left(10^{6} \mathrm{MPa} / \mathrm{s}\right)$ \\
\hline $420-5$ & 48.32 & 25.87 & 2610 & 4385 & 30.89 & 0.49 \\
$420-6$ & 48.31 & 27.78 & 2419 & 4630 & 29.32 & 0.40 \\
$420-7$ & 48.30 & 25.70 & 2630 & 4283 & 28.29 & 0.34 \\
$420-8$ & 48.30 & 28.71 & 2356 & 4557 & 21.91 & 0.27 \\
$420-13$ & 48.30 & 24.46 & 2616 & 4447 & 39.18 & 0.59 \\
$420-14$ & 48.33 & 27.06 & 2562 & 4436 & 31.65 & 0.42 \\
$420-15$ & 48.31 & 25.08 & 2623 & 4400 & 26.16 & 0.26 \\
$420-17$ & 48.32 & 25.56 & 2630 & 4564 & 29.32 & 0.45 \\
\hline
\end{tabular}

TABLE 6: Testing result of the dynamic tension test at depth $510 \mathrm{~m}$.

\begin{tabular}{lcccccc}
\hline No. & $D(\mathrm{~mm})$ & $B(\mathrm{~mm})$ & $\rho\left(\mathrm{kg} / \mathrm{m}^{3}\right)$ & $V_{\mathrm{p}}(\mathrm{m} / \mathrm{s})$ & $\sigma_{\mathrm{d}}(\mathrm{MPa})$ & Loading rate $\left(10^{6} \mathrm{MPa} / \mathrm{s}\right)$ \\
\hline $510-1$ & 48.24 & 26.64 & 2650.77 & 5223.53 & 37.55 & 0.52 \\
$510-2$ & 48.30 & 26.73 & 2645.49 & 5043.40 & 31.10 & 0.41 \\
$510-3$ & 48.26 & 26.67 & 2625.08 & 5229.41 & 12.95 & 0.13 \\
$510-5$ & 48.26 & 26.63 & 2649.56 & 5547.92 & 32.15 & 0.40 \\
$510-6$ & 48.27 & 27.03 & 2599.16 & 5198.08 & 36.74 & 0.64 \\
\hline
\end{tabular}

Among them, the serial number, diameter, thickness, density, wave velocity, dynamic tensile strength, and specific loading rate of rock samples at a certain depth are all shown in Tables 2-9. According to the test results, the loading rate of the granite is generally in the order of $10^{5} \mathrm{MPa} / \mathrm{s}$, which is a middle and high loading rate level.

The dynamic tensile strength is generally between $15 \mathrm{MPa} 35 \mathrm{MPa}$. Furthermore, at the different loading rates, 
TABLe 7: Testing result of the dynamic tension test at depth $520 \mathrm{~m}$.

\begin{tabular}{lcccccc}
\hline No. & $D(\mathrm{~mm})$ & $B(\mathrm{~mm})$ & $\rho\left(\mathrm{kg} / \mathrm{m}^{3}\right)$ & $V_{\mathrm{p}}(\mathrm{m} / \mathrm{s})$ & $\sigma_{\mathrm{d}}(\mathrm{MPa})$ & Loading rate $\left(10^{6} \mathrm{MPa} / \mathrm{s}\right)$ \\
\hline $520-1$ & 48.31 & 26.40 & 2615.43 & 5387.76 & 20.53 & 0.16 \\
$520-2$ & 48.28 & 26.72 & 2658.90 & 5138.46 & 21.52 & 0.16 \\
$520-3$ & 48.32 & 26.78 & 2638.37 & 5465.31 & 27.21 & 0.32 \\
$520-4$ & 48.63 & 26.54 & 2567.51 & 5007.55 & 27.04 & 0.38 \\
$520-5$ & 48.33 & 26.38 & 2635.92 & 5073.08 & 28.22 & 0.35 \\
$520-6$ & 48.35 & 26.45 & 2657.67 & 5290.00 & 29.05 & 0.59 \\
$520-7$ & 48.34 & 26.36 & 2636.83 & 5272.00 & 29.64 & 0.46 \\
\hline
\end{tabular}

TABLe 8: Testing result of the dynamic tension test at depth $530 \mathrm{~m}$.

\begin{tabular}{lcccccc}
\hline No. & $D(\mathrm{~mm})$ & $B(\mathrm{~mm})$ & $\rho\left(\mathrm{kg} / \mathrm{m}^{3}\right)$ & $V_{\mathrm{p}}(\mathrm{m} / \mathrm{s})$ & $\sigma_{\mathrm{d}}(\mathrm{MPa})$ & Loading rate $\left(10^{6} \mathrm{MPa} / \mathrm{s}\right)$ \\
\hline $530-1$ & 48.24 & 27.15 & 2711.87 & 5323.53 & 20.67 & 0.12 \\
$530-2$ & 48.31 & 26.04 & 2641.11 & 5208.00 & 27.39 & 0.37 \\
$530-3$ & 48.29 & 26.42 & 2625.95 & 5284.00 & 27.57 & 0.35 \\
$530-4$ & 48.27 & 27.39 & 2664.80 & 5167.92 & 28.04 & 0.41 \\
$530-5$ & 48.50 & 27.43 & 2635.74 & 5175.47 & 28.55 & 0.37 \\
$530-6$ & 48.41 & 26.49 & 2616.31 & 5094.23 & 25.80 & 0.44 \\
$530-7$ & 48.15 & 27.50 & 2697.36 & 5392.16 & 35.87 & 0.54 \\
\hline
\end{tabular}

TABLE 9: Testing result of the dynamic tension test at depth $540 \mathrm{~m}$.

\begin{tabular}{lcccccc}
\hline No. & $D(\mathrm{~mm})$ & $B(\mathrm{~mm})$ & $\rho\left(\mathrm{kg} / \mathrm{m}^{3}\right)$ & $V_{\mathrm{p}}(\mathrm{m} / \mathrm{s})$ & $\sigma_{\mathrm{d}}(\mathrm{MPa})$ & Loading rate $\left(10^{6} \mathrm{MPa} / \mathrm{s}\right)$ \\
\hline $540-2$ & 48.33 & 26.86 & 2598.97 & 4069.70 & 20.34 & 0.26 \\
$540-3$ & 48.22 & 26.95 & 2571.63 & 4990.74 & 22.54 & 0.29 \\
$540-4$ & 48.27 & 26.24 & 2646.16 & 4100.00 & 23.09 & 0.30 \\
$540-5$ & 48.39 & 27.10 & 2609.72 & 3871.43 & 25.93 & 0.33 \\
$540-8$ & 48.12 & 26.74 & 2623.18 & 5142.31 & 27.38 & 0.40 \\
\hline
\end{tabular}

TABLe 10: Testing result of the dynamic tension test at depth $580 \mathrm{~m}$.

\begin{tabular}{lcccccc}
\hline No. & $D(\mathrm{~mm})$ & $B(\mathrm{~mm})$ & $\rho\left(\mathrm{kg} / \mathrm{m}^{3}\right)$ & $V_{\mathrm{p}}(\mathrm{m} / \mathrm{s})$ & $\sigma_{\mathrm{d}}(\mathrm{MPa})$ & Loading rate $\left(10^{6} \mathrm{MPa} / \mathrm{s}\right)$ \\
\hline $580-2$ & 48.28 & 26.74 & 2656.92 & 4383.61 & 24.05 & 0.23 \\
$580-3$ & 48.27 & 26.90 & 2642.21 & 4138.46 & 28.50 & 0.35 \\
$580-4$ & 48.26 & 26.74 & 2638.66 & 4312.90 & 24.80 & 0.25 \\
$580-5$ & 48.23 & 26.43 & 2631.49 & 4066.15 & 27.63 & 0.38 \\
$580-7$ & 48.17 & 26.65 & 2657.48 & 4164.06 & 31.68 & 0.43 \\
\hline
\end{tabular}

the dynamic tensile strength with diverse depth shows the same change rule, that is, the dynamic tensile strength increases with the loading rate. Thus, the dynamic rate effect of brittle materials has been further verified.

A typical waveform is shown in Figure 3. The relationship between dynamic tensile strength and loading rate of granite samples with depth of $350 \mathrm{~m}$ is shown in Figure 4. It can be seen that the dynamic tensile strength increases with the loading rate, and basically it shows a tendency of linear growth.

The relationship between dynamic tensile strength and loading rate with buried depth of $360 \mathrm{~m}, 380 \mathrm{~m}, 420 \mathrm{~m}$, $510 \mathrm{~m}, 520 \mathrm{~m}, 530 \mathrm{~m}, 540 \mathrm{~m}$, and $580 \mathrm{~m}$ is shown in Figures 5-12. And the same experimental rule was found, that is, with the increase of loading rates, the dynamic tensile strengths also show an increasing trend.

All those tests are carried out under a similar condition. The position of the projectile is fixed, and the loading pressure is slightly changed. Therefore, the loading rate is basically maintained at the same level.

As it is well known, the failure mode of rock reflects its stress state. The Brazilian disc specimen is split into two parts along the middle direction during the static indirect tensile test.

Through the observation of the failure mode after dynamic tensile test, it is found that at the initial stage of loading, some microcracks were produced, mainly located in the middle of the specimen. With the loading process, the stress wave reflects back and forth inside the specimen, which leads to the expansion of the initial crack, and then propagates rapidly. The extension direction is always along the central part of the specimen and crack extends to the two ends. As the loading continued, it is eventually ruptured into two halves.

Through the dynamic tensile test, it is found that the failure patterns of rock samples are as follows: when the 


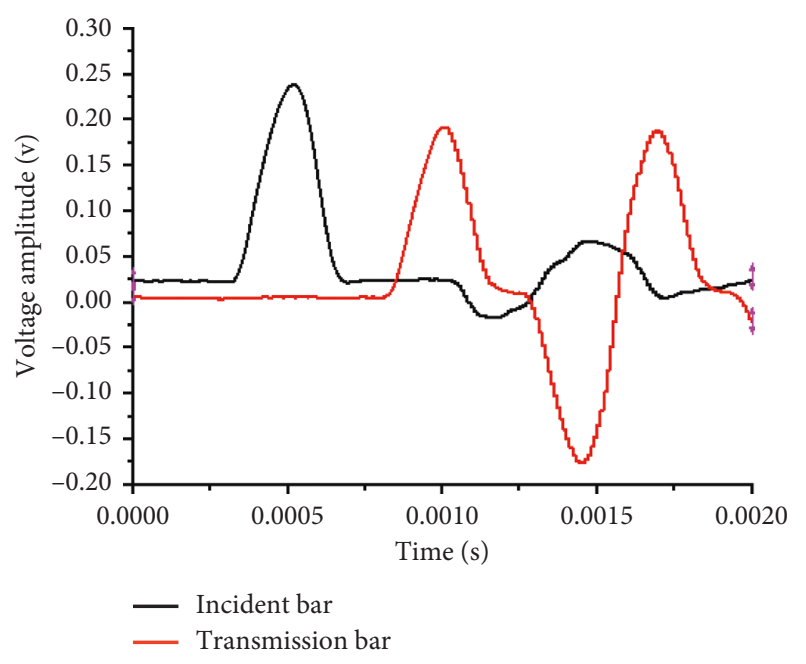

Figure 3: Typical waveform of rock specimen under dynamic tensile test.

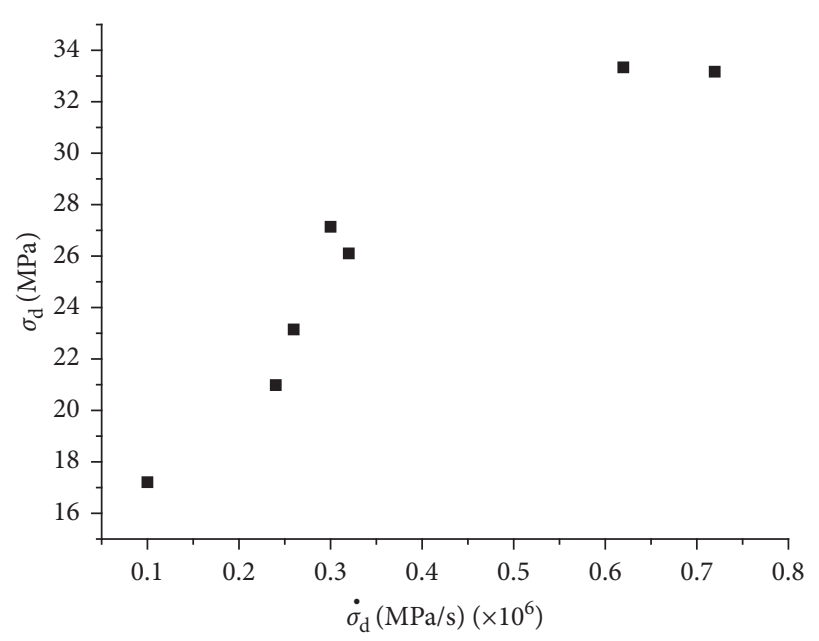

FIGURE 4: Relationship between dynamic tension strength and loading rate at depth $350 \mathrm{~m}$.

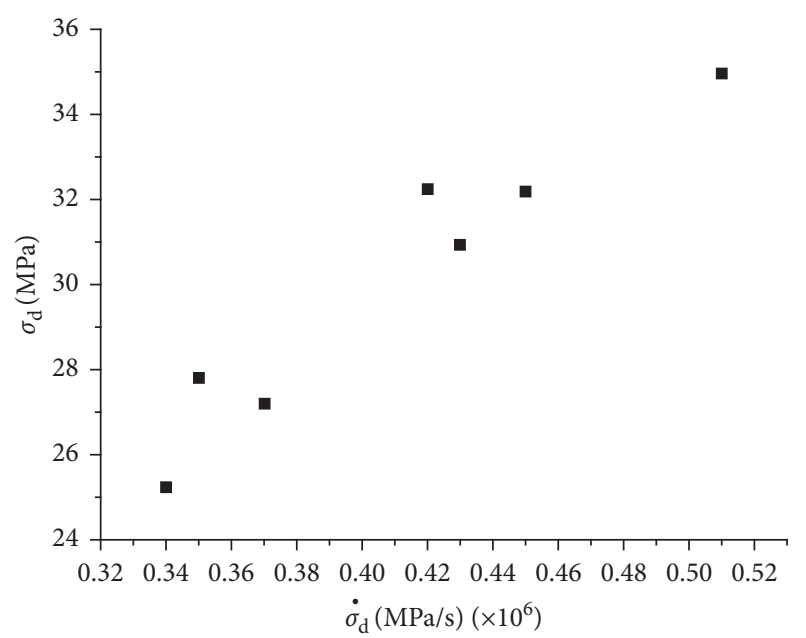

FIGURE 5: Relationship between dynamic tension strength and loading rate at depth $360 \mathrm{~m}$.

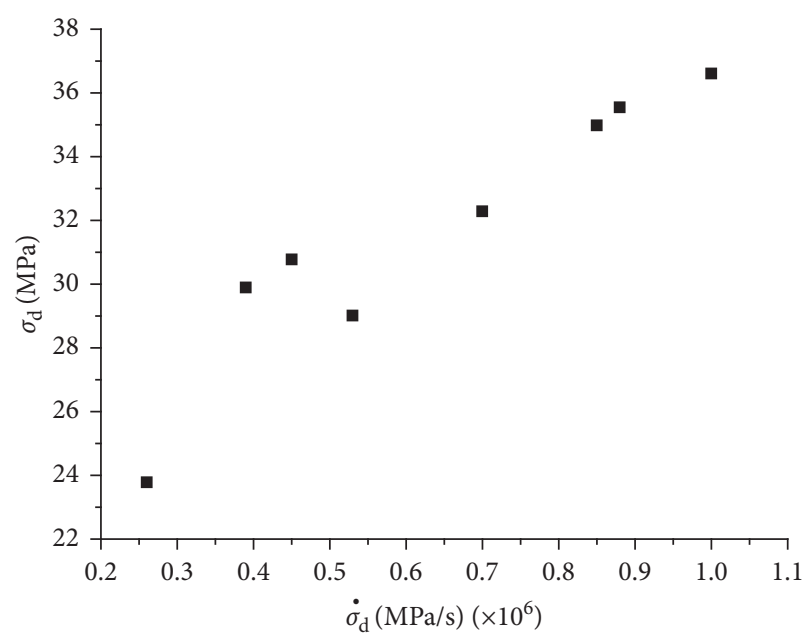

FIgURE 6: Relationship between dynamic tension strength and loading rate at depth $380 \mathrm{~m}$.

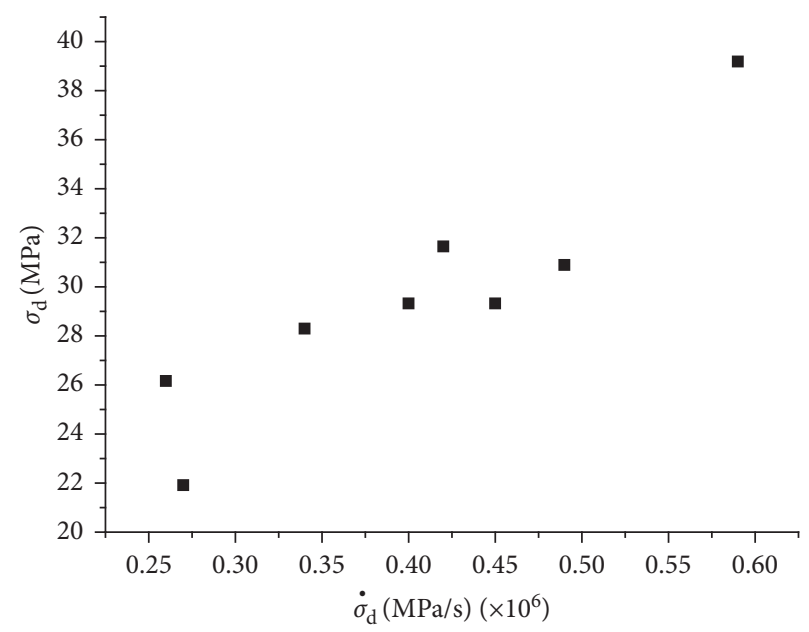

FIgURE 7: Relationship between dynamic tension strength and loading rate at depth $420 \mathrm{~m}$.

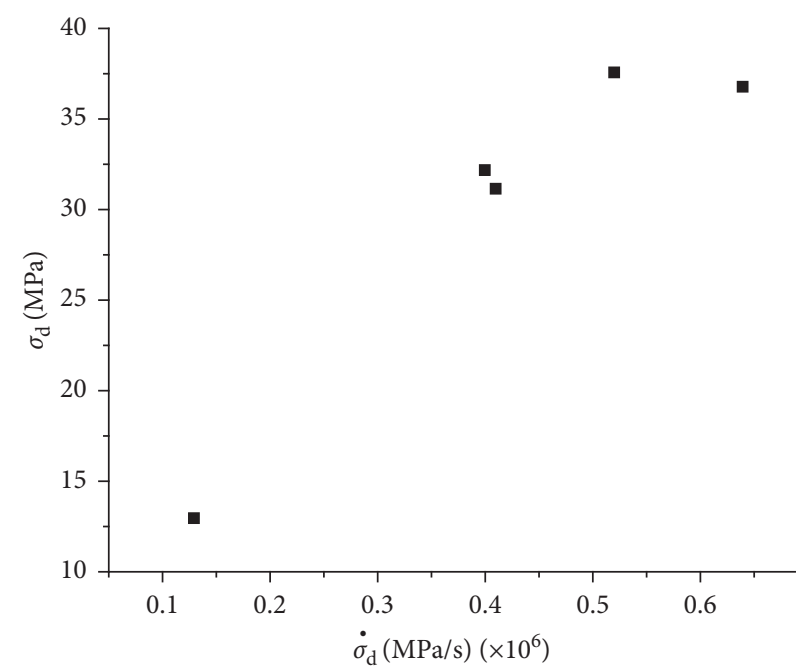

FIgURE 8: Relationship between dynamic tension strength and loading rate at depth $510 \mathrm{~m}$. 


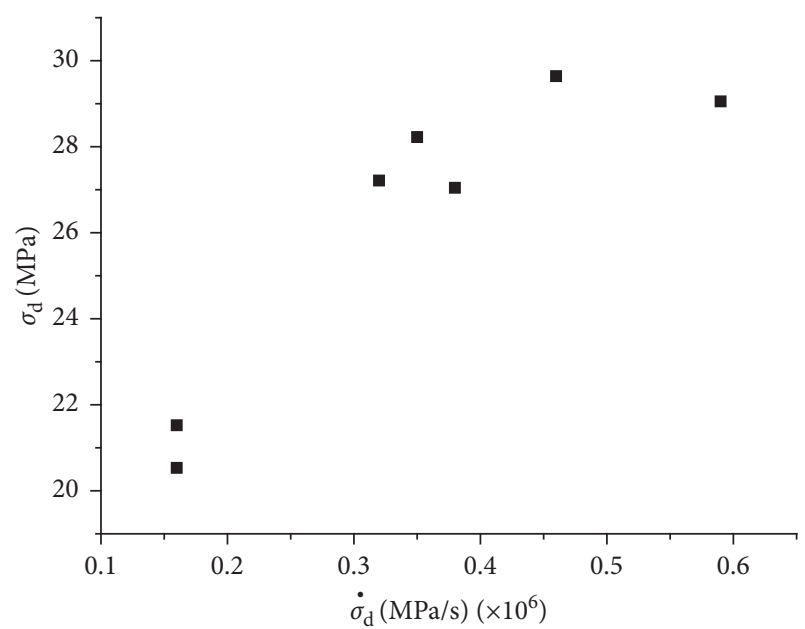

FIGURE 9: Relationship between dynamic tension strength and loading rate at depth $520 \mathrm{~m}$.

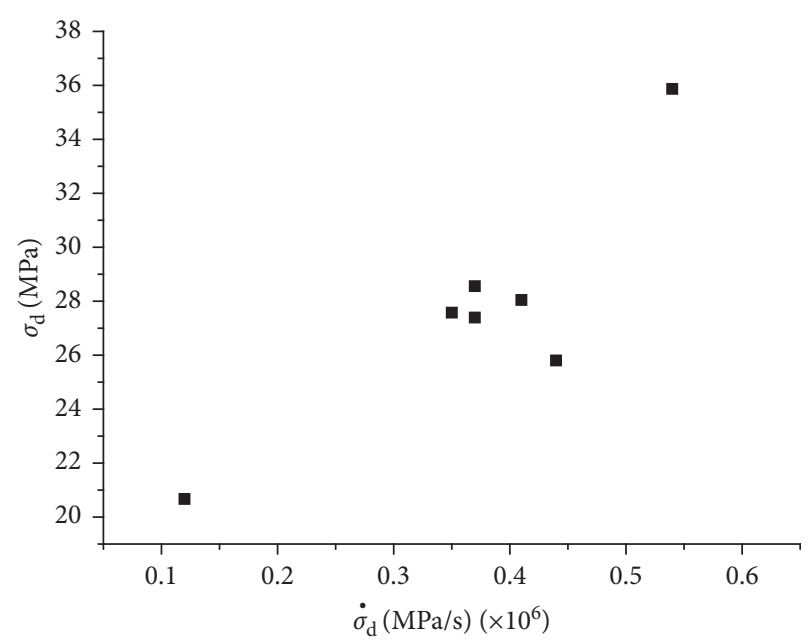

FIgURE 10: Relationship between dynamic tension strength and loading rate at depth $530 \mathrm{~m}$.

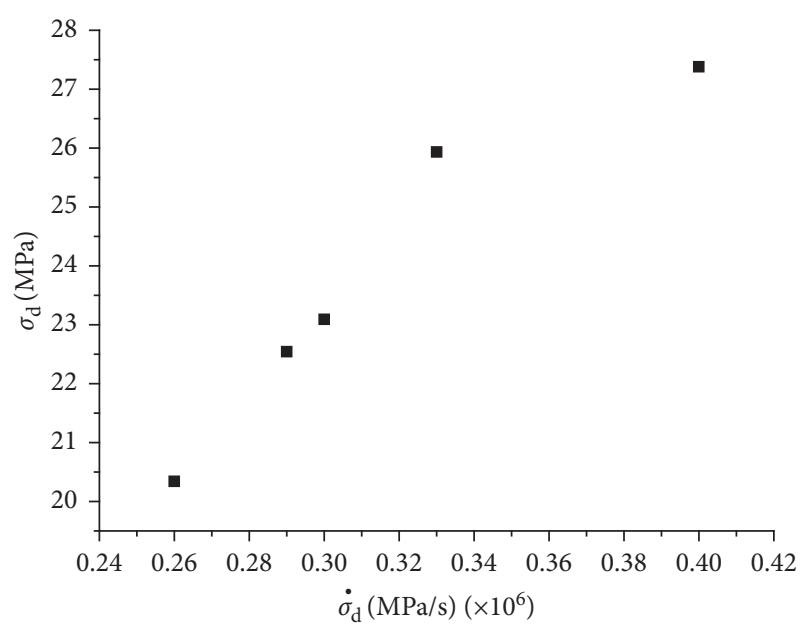

FIGURE 11: Relationship between dynamic tension strength and loading rate at depth $540 \mathrm{~m}$.

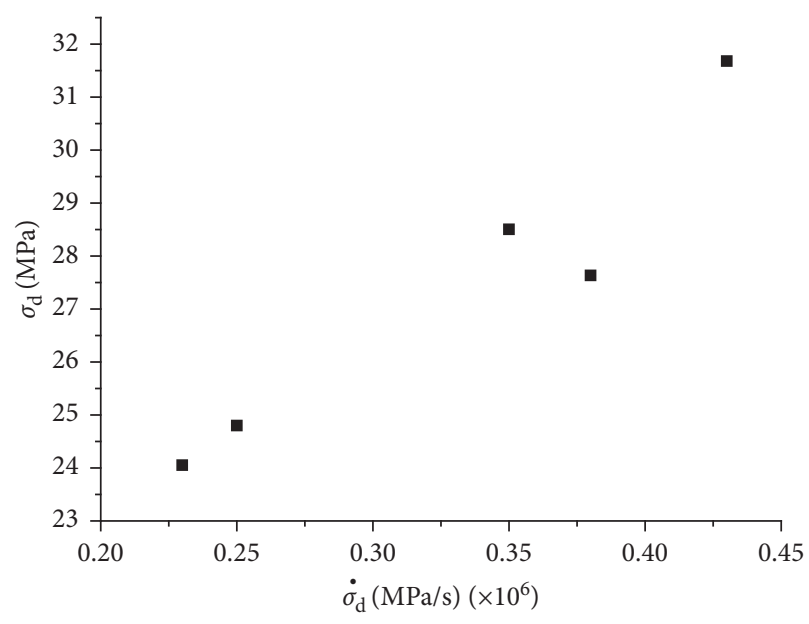

FIgURE 12: Relationship between dynamic tension strength and loading rate at depth $580 \mathrm{~m}$.

impact load is not large, the rock often breaks into two halves. With the increase of the impact load, the number of rock fragments increases and the fractal size is generally uniform, as shown in Figure 13. It also confirms that the dynamic loading strength is higher than the static loading strength. Under the action of dynamic load, the number of cracks which can withstand the damage is more than that under static load, so the dynamic strength is higher than the static strength. In short, the failure mode of rock under dynamic tensile condition is basically tensile pattern.

4.2. Characteristic of the Dynamic Tensile Strength at Different Depths. As a brittle material, the tensile strength of rock is much lower than the compressive strength, which has been widely applied in engineering blasting. Taking the tunnel blasting excavation as an example, not only the fracture surface after blasting should be considered, but also the contour lines should be conformed to the design requirements and the reasonable distribution of rock fragmentation should also be considered.

When the explosive is detonated, the rock should be mainly in the tensile stress by the propagation of the explosion wave. And if the ultimate tensile strength of the rock mass is lower than the maximum shear stress, the rock is broken and crushed. Therefore, the presplitting blasting method is used to release the original stress in the rock partly, which is beneficial to achieve a good cutting blasting effect, and thus to obtain a higher blasting hole utilization rate. Under the action of blasting, the loading rate is different from that of the static load, generally $10^{5} \sim 10^{6} \mathrm{MPa} / \mathrm{s}$.

Furthermore, it is necessary to investigate the tensile properties of the areas at this loading rate. A specific loading rate $0.4 \times 10^{6} \mathrm{MPa} / \mathrm{s}$ is selected for the rock samples with different depth, and the dynamic tensile strength changed with the depth is shown in Figure 14.

From Figure 14, it is found that the dynamic tensile strength of granite increases first and then decreases with the depth in the range from $350 \mathrm{~m}$ to $580 \mathrm{~m}$. The cause for this phenomenon should be analyzed and discussed in detail 


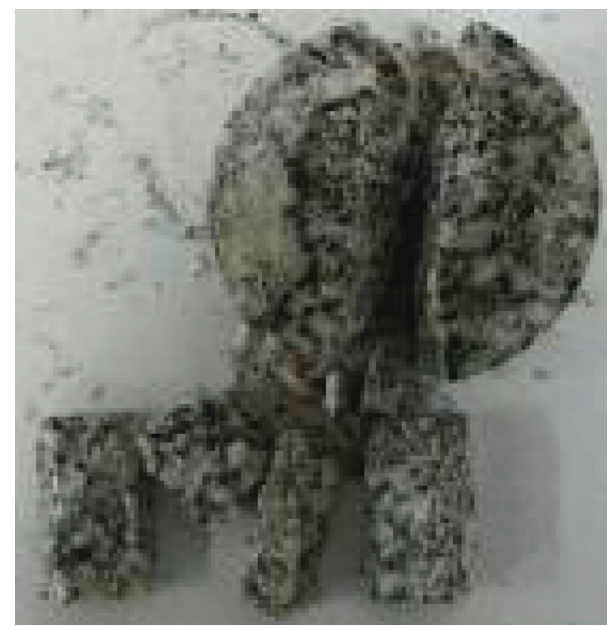

(a)

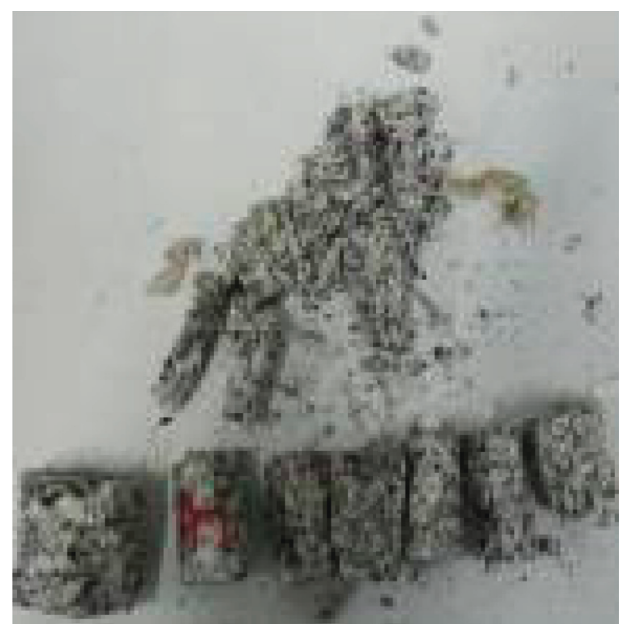

(b)

FIGURE 13: Failure forms of rock under different loading rates.

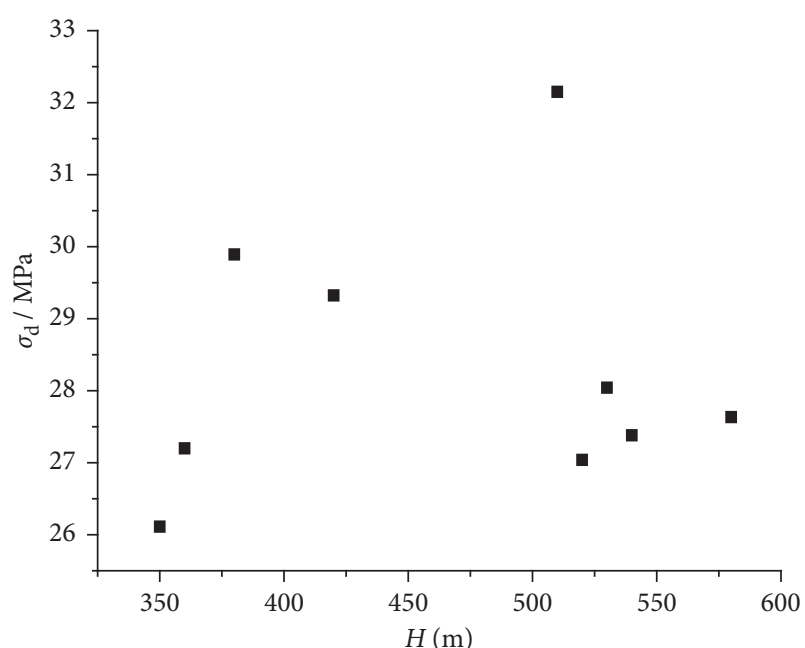

FIGURE 14: Relationship between dynamic tension strength and different depth.

from the physical and mechanical characteristics of the rock samples.

It is necessary to point out that the experiment is only for the specimen of different depth in the same borehole, so it is suitable to be compared and analyzed together.

\section{Discussion}

Under the above selected loading rate condition $(0.4 \times$ $\left.10^{6} \mathrm{MPa} / \mathrm{s}\right)$, the relationship between the dynamic tensile strength and its own density and wave velocity is shown in Figure 15, in which, the black circular data points indicate the relationship between dynamic tensile strength and wave velocity and the blue box data points indicate the relationship between dynamic tensile strength and density.

It can be seen from Figure 15 that the dynamic tensile strength is higher when the density and wave velocity of

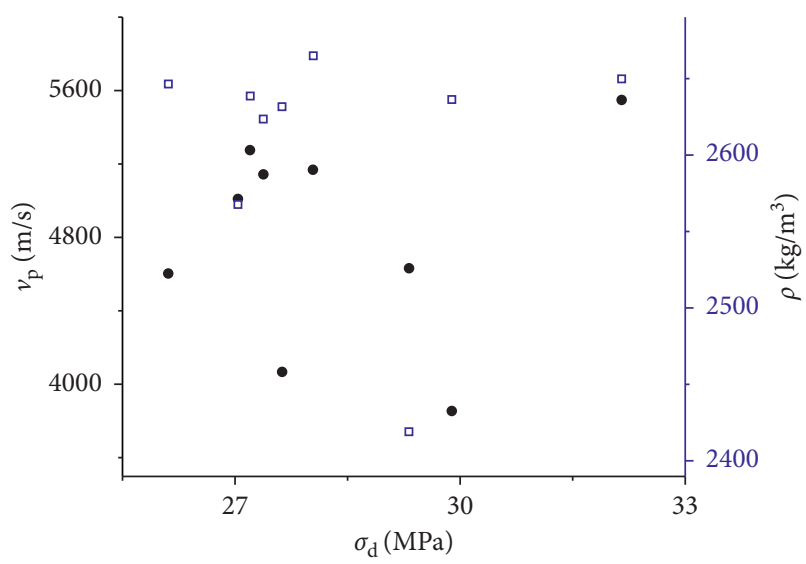

FIGURE 15: Relationship between dynamic tension strength, wave velocity, and density of rock specimen.

granite are both large. That is to say, the denser the rock is, the faster the propagation of wave velocity is and the higher the dynamic tensile strength is. When the density is low and the wave velocity is relatively low, the dynamic tensile strength is also low. When the density and wave velocity are at the middle level, the dynamic tensile strength is also within the interval range of the middle value. With the increase of the buried depth, the rock will become denser. Especially at the depth of $3000 \mathrm{~m}$, this phenomenon is much more significant.

For this test, the density obtained using the specimen is slightly different, which is confirmed by the identification and analysis of lithology under microscope, as shown in Figure 16. The granite tested is mainly composed of quartz, potash feldspar, and black mica. The quartz is granular, particle size is $1 \sim 2 \mathrm{~mm}$, and the content is about $35 \% \sim 40 \%$. The potash feldspar particle size is mainly in $1 \sim 2 \mathrm{~mm}$, with a localized $1 \mathrm{~cm}$ of potassium feldspar, the total content of potash feldspar is 55\% 65\%, and the content of black mica is about $5 \%$. 


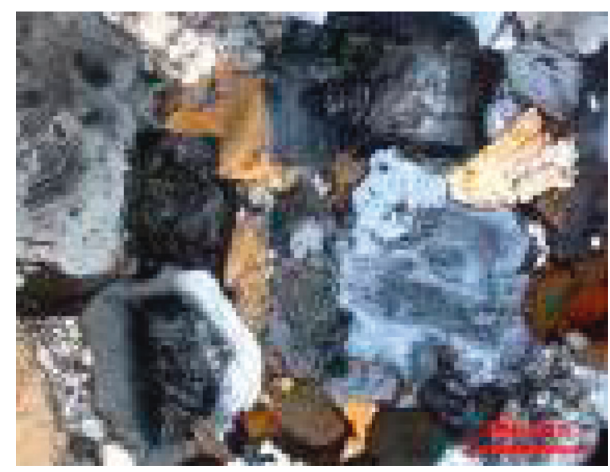

(a)

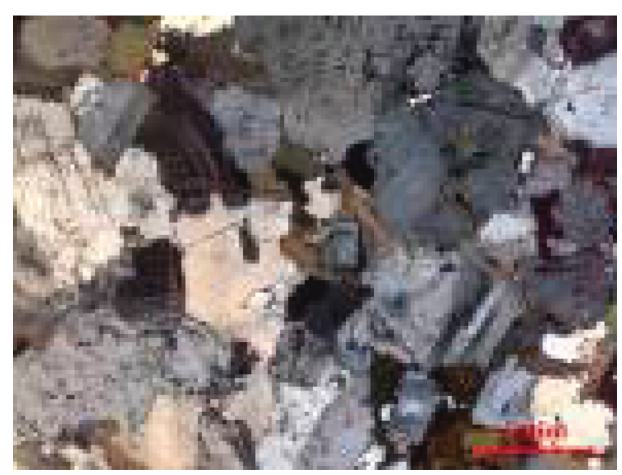

(b)

FIGURE 16: Result of the granite specimen under normal polarizing microscope.

It can be further explained that the main reason for the difference of physical and mechanical characteristics at depth of the same rock is the diverse geological environment, especially the in-site stress environment surrounding the rock. Obviously, the mechanical property of rock in different depths is determined by the rock heterogeneity. Especially under the dynamic loading rates, this difference is shown more significant. And the explanation is consistent with $\mathrm{Zhu}$ et al., who obtained it by numerical calculation [32]. The RFPA software is used to simulate the rock fracture process under dynamic load. By comparison with the fracture theory, it is shown that the heterogeneity of rock materials is one of the main reasons for the improvement of the dynamic strength.

That is to say, rock strength varied with depth is determined by the properties and external loading conditions. It cannot be simply considered that the rock strength increases first and then decreases with the depth. Not only a phenomenal expression of this test, but also the essential reason for the change of rock strength, is illustrated. It should be noticed that it is not rigorous just said the rock strength increases or decreases with the depth.

According to the above research, it is believed that as the physical characteristics of the rock have been changed gradually, the rock strength and other mechanical properties will increase or decrease with the depth. From the point of physical mechanism, the density, porosity, and others are different at diverse depths, which lead to the differences of mechanical properties.

\section{Conclusions}

(1) Based on the SHPB device, the dynamic tensile test was carried out on the granite, which is located at the depth $350 \mathrm{~m} \sim 580 \mathrm{~m}$ at the same borehole in TianHu area Xinjiang Province, the preselected site of the high-level radioactive waste geological disposal in China. Under the loading rate level of $10^{5} \mathrm{MPa} / \mathrm{s}$, the dynamic tensile strength is generally between $15 \mathrm{MPa} 35 \mathrm{MPa}$, which is of significant reference for the site selection.
(2) All the tested dynamic tensile strength increases with the loading rate, which shows the characteristic of the loading rate effect of the brittle materials. However, the relationship between the dynamic tensile strength and the depth is not a single tendency, but presents an increase first and then a decrease later.

(3) As the physical characteristics of the rock have been changed gradually, the rock strength and other mechanical properties will increase or decrease with the depth. From the point of physical mechanism, the density, porosity, and others are different at diverse depths, which lead to the differences of mechanical properties.

\section{Data Availability}

The data that support the findings of this study are available from the corresponding author upon reasonable request.

\section{Conflicts of Interest}

The authors declare that they have no conflicts of interest.

\section{Acknowledgments}

This work was supported by the National Natural Science Foundation of China (grant number 41202207). The authors are most grateful to Professors X. B. Li and Z. L. Zhou in Central South University for the valuable help with the tests.

\section{References}

[1] Z. Pan and Q. Qian, Strategic Research for Deep Geological Disposal of High Level Radioactive Waste, Atomic Energy Press, Beijing, China, 2009.

[2] J. Wang, X. Fan, G. Xu et al., Geological Disposal of High-Level Radioactive Waste in China: Progress in Last Decade, Atomic Energy Press, Beijing, China, 2004.

[3] X. Huang and J. Tao, "Tensile mechanical properties research of three construction steel bars in high strain rate," Engineering Mechanics, vol. 33, no. 7, pp. 184-189, 2016. 
[4] L. Jin and X. Du, "Meso scale numerical analysis of the effect of loading rate on the tensile failure behavior of concrete," Engineering Mechanics, vol. 32, no. 8, pp. 42-49, 2015.

[5] G. Cusatis, "Strain rate effects on concrete behavior," International Journal of Impact Engineering, vol. 38, no. 4, pp. 162-170, 2011.

[6] J. Zhao, X. B. Zhao, and J. G. Cai, "A further study of P wave attenuation across parallel fractures with linear deformational behavior," International Journal of Rock Mechanics and Mining Sciences, vol. 43, no. 5, pp. 776-788, 2006.

[7] J. Jin, X. Li, Y. Tubing et al., "Effect of axial static stress of elastic bar on incident stress wave under axial impact loading," Engineering Mechanics, vol. 30, no. 11, pp. 21-27, 2013.

[8] H. Xie and Z. Chen, Rock Mechanics, Science Press, Beijing, China, 2004.

[9] H. Zhou, H. Xie, Z. Zuo, and K. Man, "Experimental study of the effect of depth on mechanical parameters of rock," Science China, vol. 55, no. 34, pp. 3276-3284, 2010.

[10] C. Jiang, Z. Jiang, H. Liu et al., "Study on the relationship between mechanical parameters of granite and occurrence depth of rock mass," Stone, vol. 7, pp. 4-6, 2004.

[11] F. Dai, K. Xia, and L. Tang, "Rate dependence of the flexural tensile strength of Laurentian granite," International Journal of Rock Mechanics and Mining Sciences, vol. 47, no. 3, pp. 469-475, 2010.

[12] Y. Yu, J. Zhang, and J. Zhang, "A modified brazilian disk tension test," International Journal of Rock Mechanics and Mining Sciences, vol. 46, no. 2, pp. 421-425, 2009.

[13] B. Whittaker, R. Singh, and G. Sun, Rock Fracture Mechanics: Principles, Design and Applications, Elsevier, Amsterdam, Netherlands, 1992.

[14] X. Li, Z. Zhou, T. S. Lok, L. Hong, and T. Yin, "Innovative testing technique of rock subjected to coupled static and dynamic loads," International Journal of Rock Mechanics and Mining Sciences, vol. 45, no. 5, pp. 739-748, 2008.

[15] X. Li, Z. Zhou, Z. Ye et al., "Study of rock mechanical characteristics under coupled static and dynamic loads," Chinese Journal of Rock Mechanics and Engineering, vol. 27, no. 7, pp. 1387-1395, 2008.

[16] H. Li, J. Zhao, and T. J. Li, "Micromechanical modeling of the mechanical properties of a granite under dynamic uniaxial compressive loads," International Journal of Rock Mechanics and Mining Sciences, vol. 37, no. 6, pp. 923-935, 2000.

[17] Y. Zuo, X. Li, C. Tang et al., "Experimental investigation on failure of rock subjected to 2D dynamic-static coupling loading," Chinese Journal of Rock Mechanics and Engineering, vol. 25, no. 9, pp. 1809-1820, 2006.

[18] S. Liu, H. Li, J. Li et al., "Experimental investigation on rock dynamic mechanics properties under axial tension," Chinese Journal of Geotechnical Engineering, vol. 29, no. 12, pp. 1904-1907, 2007.

[19] X. Li, Y. Zuo, and C. Ma, "Constitutive model of rock subjected to static-dynamic coupling loadings under intermediate strain rate," Chinese Journal of Rock Mechanics and Engineering, vol. 25, no. 2, pp. 865-874, 2006.

[20] X. Li, F. Gong, J. Zhao et al., "Test study of impact failure of rock subjected to one-dimensional coupled static and dynamic loads," Chinese Journal of Rock Mechanics and Engineering, vol. 29, no. 2, pp. 251-260, 2010.

[21] H. Li, J. Zhao, and T. J. Li, "Triaxial compression tests on a granite at different strain rates and confining pressures," International Journal of Rock Mechanics and Mining Sciences, vol. 36, no. 8, pp. 1057-1063, 1999.
[22] X. Li and D. Gu, Rock Impact Dynamics, Press of Central South University of Technology, Changsha, China, 1994.

[23] H. Ozturk and D. D. Tannant, "Influence of rock properties and environmental conditions on thin spray-on liner adhesive bond," International Journal of Rock Mechanics and Mining Sciences, vol. 48, no. 7, pp. 1196-1198, 2011.

[24] J. Weerheijm and J. C. A. M. Van Doormaal, "Tensile failure of concrete at high loading rates: new test data on strength and fracture energy from instrumented spalling tests," International Journal of Impact Engineering, vol. 34, no. 3, pp. 609-626, 2007.

[25] L. Luo, X. Li, M. Tao, and L. Dong, "Mechanical behavior of rock-shotcrete interface under static and dynamic tensile loads," Tunnelling and Underground Space Technology, vol. 65, pp. 215-224, 2017.

[26] H. Zhou, Y. Yang, H. Xiao et al., "Research on loading rate effect of tensile strength property of hard brittle marble-test characteristics and mechanism," Chinese Journal of Rock Mechanics and Engineering, vol. 32, no. 9, pp. 1868-1875, 2013.

[27] K. Man and H. Zhou, "Research on dynamic fracture toughness and tensile strength of rock at different depths," Chinese Journal of Rock Mechanics and Engineering, vol. 29, no. 8, pp. 1657-1663, 2010.

[28] K. Man, X. Liu, F. Gong et al., "Research on the static and dynamic properties of the granite in XinJiang province TianHu area for the geological disposal of High level radioactive waste," Journal of Vibration and Shock, vol. 36, no. 17, pp. 146-156, 2017.

[29] GB/T 50266-2013, Standard for Test Methods of Engineering Rock Masses, Research Institute of Standards and Norms, Beijing, China, 2013.

[30] F. Gong and X. Li, "Study under one-dimensional coupled static and dynamic loads," Chinese Journal of Rock Mechanics and Engineering, vol. 29, no. 10, pp. 2076-2085, 2010.

[31] F. Gong, Experimental Study on Rock Dynamic Characteristics and Dynamic Strength Criteria under Combined Static and Dynamic Loading, Central South University, Changsha, China, 2010.

[32] W. Zhu, M. Pang, Z. Huang, and C. Tang, "Numerical simulation on dynamic rock spalling," Journal of Northeastern University, vol. 27, no. 5, pp. 552-555, 2006. 


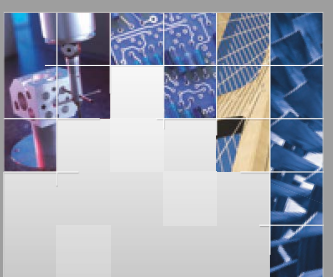

\section{Enfincering}
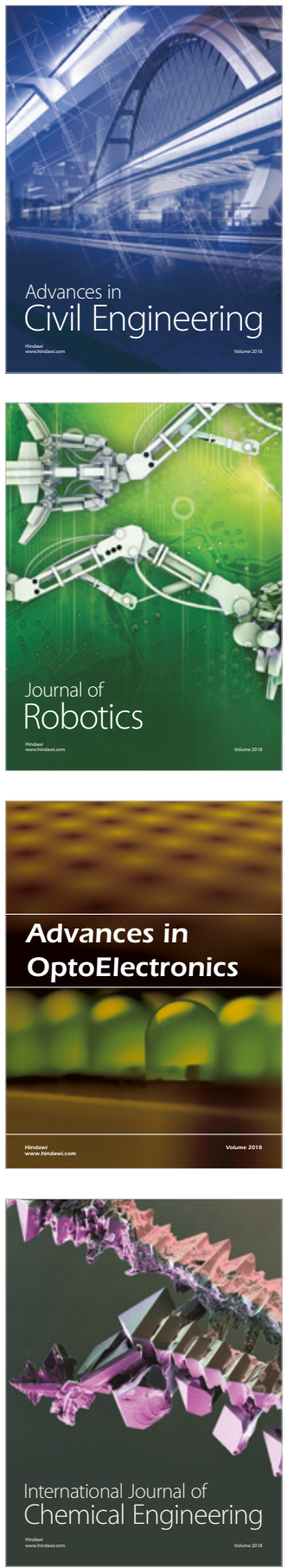

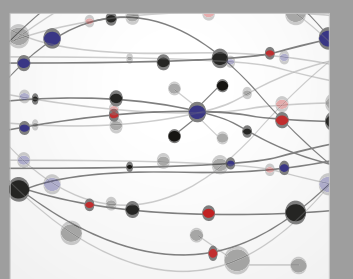

\section{Rotating \\ Machinery}

The Scientific World Journal

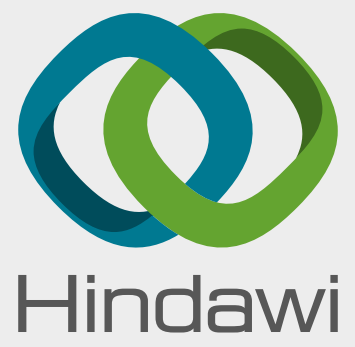

Submit your manuscripts at

www.hindawi.com
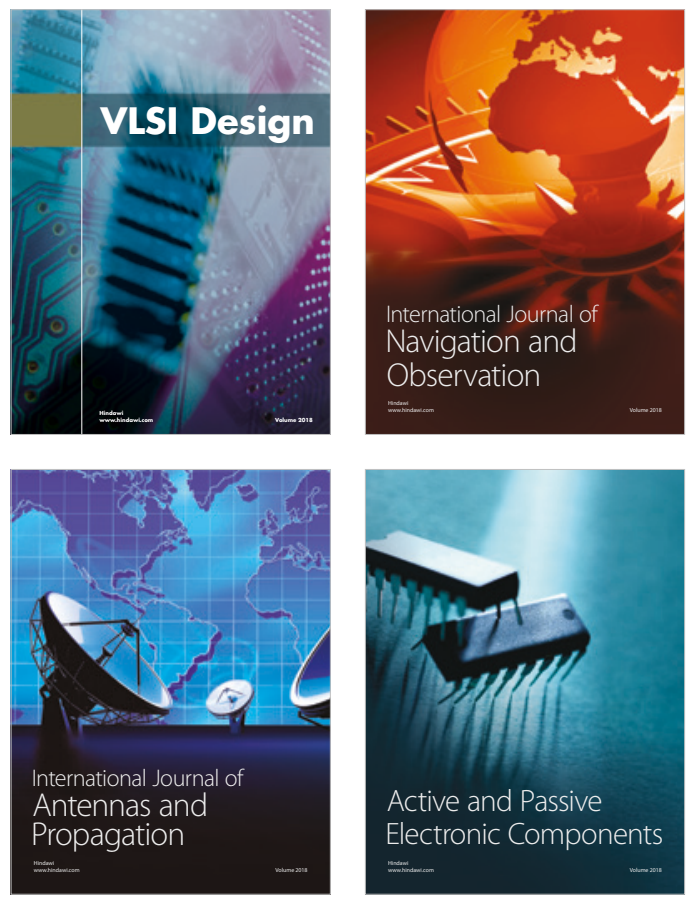
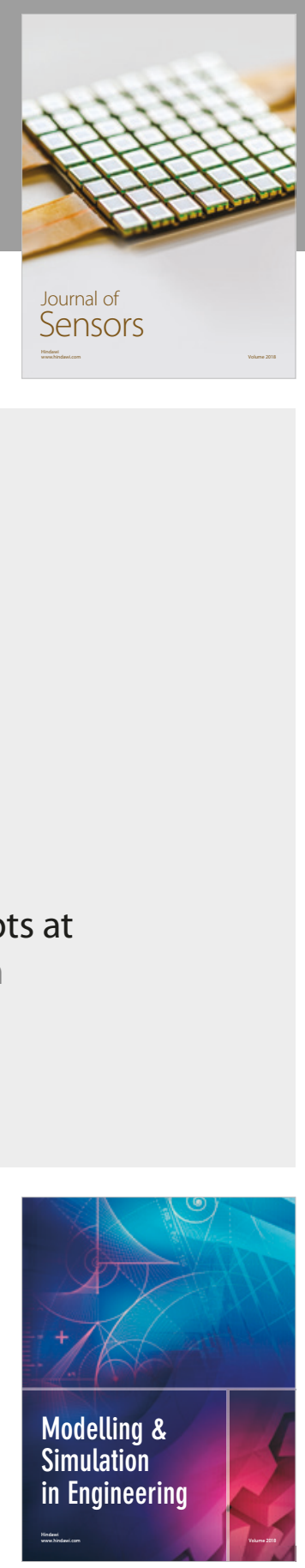

\section{Advances \\ Multimedia}
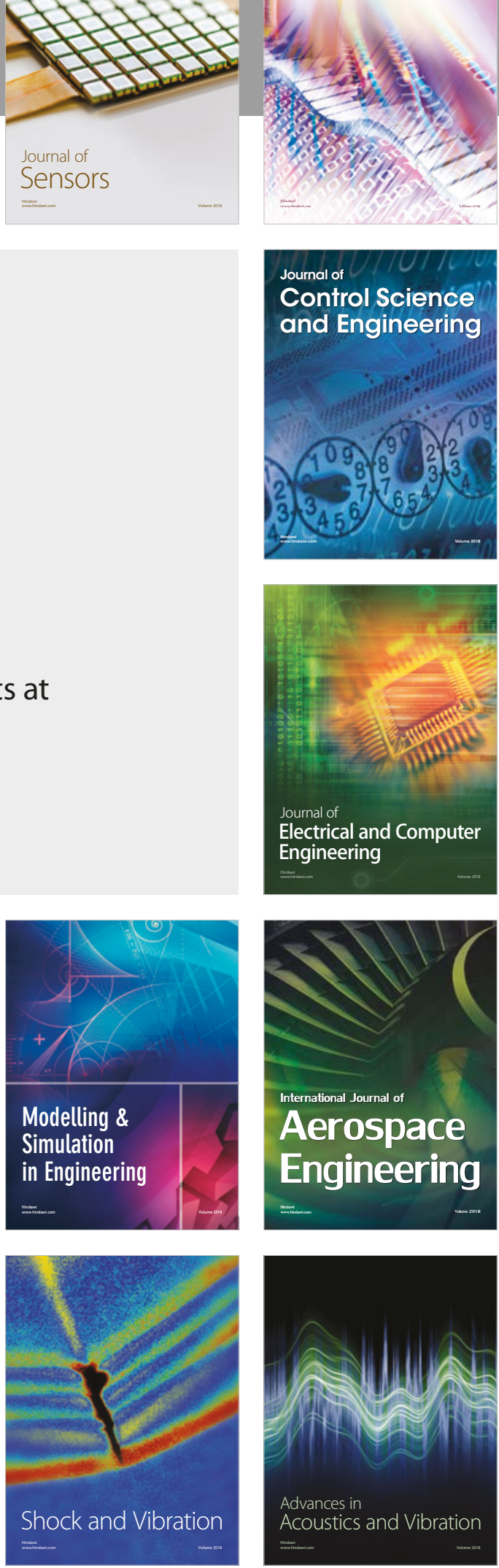